\title{
CARACTERIZAÇÃO ESPACIAL DAS ÁREAS SUSCETÍVEIS A INUNDAÇÕES E ENXURRADAS NA BACIA HIDROGRÁFICA DO RIO TAQUARI-ANTAS
}

\author{
SPATIAL CHARACTERIZATION OF SUSCEPTIBLE AREAS TO FLOODS AND FLASH FLOODS \\ IN THE TAQUARI-ANTAS RIVER BASIN
}

\section{Guilherme Garcia de OLIVEIRA ${ }^{1}$, Rafael Rodrigo ECKHARDT ${ }^{2}$, Claus HAETINGER, Augusto ALVES ${ }^{2}$}

${ }^{1}$ Universidade Federal do Rio Grande do Sul. Porto Alegre, Rio Grande do Sul, Brasil. Email: g.g.oliveira10@gmail.com

${ }^{2}$ Universidade do Vale do Taquari. Lageado, Rio Grande do Sul, Brasil.

Emails: rafare@univates.br; chaet@univates.br; augustoalves@univates.br

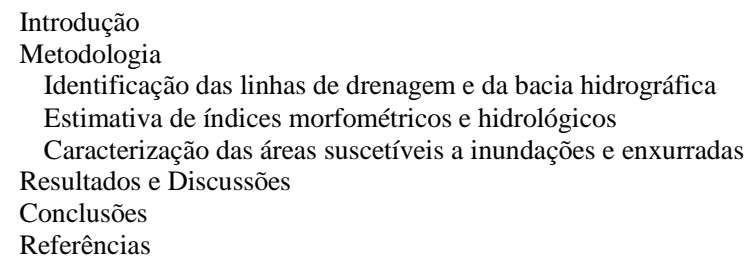

RESUMO - A identificação de áreas suscetíveis às inundações são medidas essenciais para o planejamento de municípios ribeirinhos, pois pode auxiliar no redirecionamento das atividades humanas e do crescimento do perímetro urbano para áreas menos perigosas. $\mathrm{O}$ objetivo deste estudo foi mapear e caracterizar as áreas suscetíveis a inundações e enxurradas na bacia do rio Taquari-Antas, RS. Foram estimados índices morfométricos e hidrológicos como o tempo de concentração e as vazões máximas em diferentes tempos de retorno (TRs). O mapeamento das áreas suscetíveis foi realizado por meio da simulação do aumento do nível da água nos rios. As vazões máximas foram obtidas por regionalização de vazões. Com base nos resultados obtidos, a vazão máxima anual do rio Taquari se aproxima de $7.900 \mathrm{~m}^{3} / \mathrm{s}$ no seu trecho final, podendo atingir mais de $20.000 \mathrm{~m}^{3} / \mathrm{s} \mathrm{em}$ TRs maiores. No rio Taquari, as inundações predominam, enquanto que os principais afluentes apresentam características que indicam a ocorrência tanto de inundações quanto de enxurradas. Quanto aos pontos referentes apenas às enxurradas, os mesmos estão bem distribuídos pela bacia, embora predominem em pequenas bacias da porção centro-jusante. Cerca de $8 \%$ da área da bacia pode ser atingida por eventos hidrológicos, predominando usos agropecuários, banhados, mata ciliar e florestas exóticas. Considerando as áreas urbanas suscetíveis $\left(69 \mathrm{~km}^{2}\right)$, se destacaram as cidades de Estrela, Lajeado, Venâncio Aires e Arroio do Meio.

Palavras-chave: Desastres, Geoprocessamento, Hidrologia.

\begin{abstract}
The identification of areas susceptible to flooding are essential measures for the planning of riparian municipalities, as it can help in the redirection of human activities and the growth of the urban perimeter to less dangerous areas. The aim of this study was to map and characterize the susceptible areas to floods and flash floods in Taquari-Antas River Basin. Some hydrological and morphometric indices such as the concentration time and maximum flows associated with different return times (RTs) were estimated for the basin. The mapping of areas susceptible was performed by simulating the rising water level in rivers. The maximum discharges were obtained through a flow regionalization process. Based on the results obtained, the maximum annual flow of the Taquari River approaches $7,900 \mathrm{~m}^{3} / \mathrm{s}$ in their final section, reaching values greater than $20,000 \mathrm{~m}^{3} / \mathrm{s}$ at higher RTs. In Taquari River are predominant the floods, while the main tributaries have characteristics that indicate the occurrence of both floods as of flash floods. As for the points relating only to flash floods, they are regularly distributed by the basin, although dominant in small basins of the central-downstream portion. Such hydrological events, predominantly agricultural uses, wetlands, riparian areas and exotic forests can achieve approximately $8 \%$ of the total area of the basin. The municipalities with the highest affected urban area were Estrela, Lajeado, Venâncio Aires and Arroio do Meio, considering only susceptible urban areas $\left(69 \mathrm{~km}^{2}\right)$.
\end{abstract}

Keywords: Disasters, Geoprocessing, Hydrology.

\section{INTRODUÇÃO}

As inundações e enxurradas são originadas por precipitações extremas e constituem-se em fenômenos de ocorrência natural e periódica em todos os ambientes fluviais (Castro, 1998; Oliveira, 2010). Apesar de estes fenômenos ocorrerem naturalmente, diversos estudos (Alcántara-Ayala, 2002; Marengo, 2010; UNESCO, 2012; CRED, 2015) confirmam o aumento da frequência em que estes fenômenos causam impactos negativos na sociedade, seja pela maior exposição da população às ameaças naturais, ou pelas alterações que as atividades humanas provocam na superfície das bacias hidrográficas e no sistema hidrológico como um todo.

Quando as águas do rio se elevam até a altura de suas margens, contudo sem transbordar para as áreas adjacentes, afirma-se que ocorreu uma enchente (Frank et al., 2009). Logo, as expressões enchentes e cheias são sinônimas (Santos, 2007), caracterizando o mesmo fenômeno, que consiste na elevação do nível do rio dentro do leito menor, sem que ocorra o extravasamento (Tucci et al., 2008). 
A partir do momento em que as águas transbordam, atingindo o leito maior ou a planície de inundação, é correto afirmar que ocorreu uma inundação (Frank et al., 2009; Oliveira, 2010; Tucci, 2014). As enxurradas se diferenciam das inundações principalmente pelo tempo de duração do evento, mais reduzido em virtude da elevada velocidade do fenômeno, e pela variação brusca na vazão do rio, tendo um poder destrutivo muito superior às inundações nas áreas suscetíveis a tais fenômenos (Castro, 1998; Sirangelo, 2014).

As inundações e as enxurradas, quando ocorrem em áreas com elevado grau de exposição da população e a mesma se encontra em condições mais vulneráveis, podem provocar a ocorrência de desastres. Dentre todas as classes de desastres naturais, os provocados por eventos extremos hidrológicos estão entre mais devastadores do mundo, levando a prejuízos econômicos e sociais superiores a qualquer outro tipo de desastre (Irimescu et al., 2010). Os municípios ribeirinhos sofrem uma série de impactos negativos nos períodos de precipitações extremas, quando corridas de detritos invadem os fundos de vales e a água dos rios avança sobre as cidades, causando danos em equipamentos públicos, a paralisação de atividades econômicas, além de outras perdas materiais e humanas (Oliveira et al., 2012).

A bacia hidrográfica do rio Taquari-Antas (Figura 1) é a principal área de contribuição da Região Hidrográfica do Guaíba, Rio Grande do Sul. A bacia se limita entre as latitudes $28^{\circ} 10^{\prime} \mathrm{e}$ $29^{\circ} 57^{\prime} \mathrm{S}$ e as longitudes $49^{\circ} 55^{\prime}$ e $52^{\circ} 38^{\prime}$, em uma área de drenagem de $26.428 \mathrm{~km}^{2}$. O rio TaquariAntas pode ser subdividido em dois grandes trechos: i) na porção a montante, sob a denominação de rio das Antas, está predominantemente encaixado em um vale montanhoso, alternando poços e corredeiras, eventualmente intercalados por saltos de pequeno porte, com seu percurso marcado por um forte controle estrutural e litológico; ii) na porção a jusante, sob a denominação de rio Taquari, o vale é formado predominantemente por depósitos colúvio-aluvionares, possuindo em alguns trechos extensas planícies e terraços fluviais.

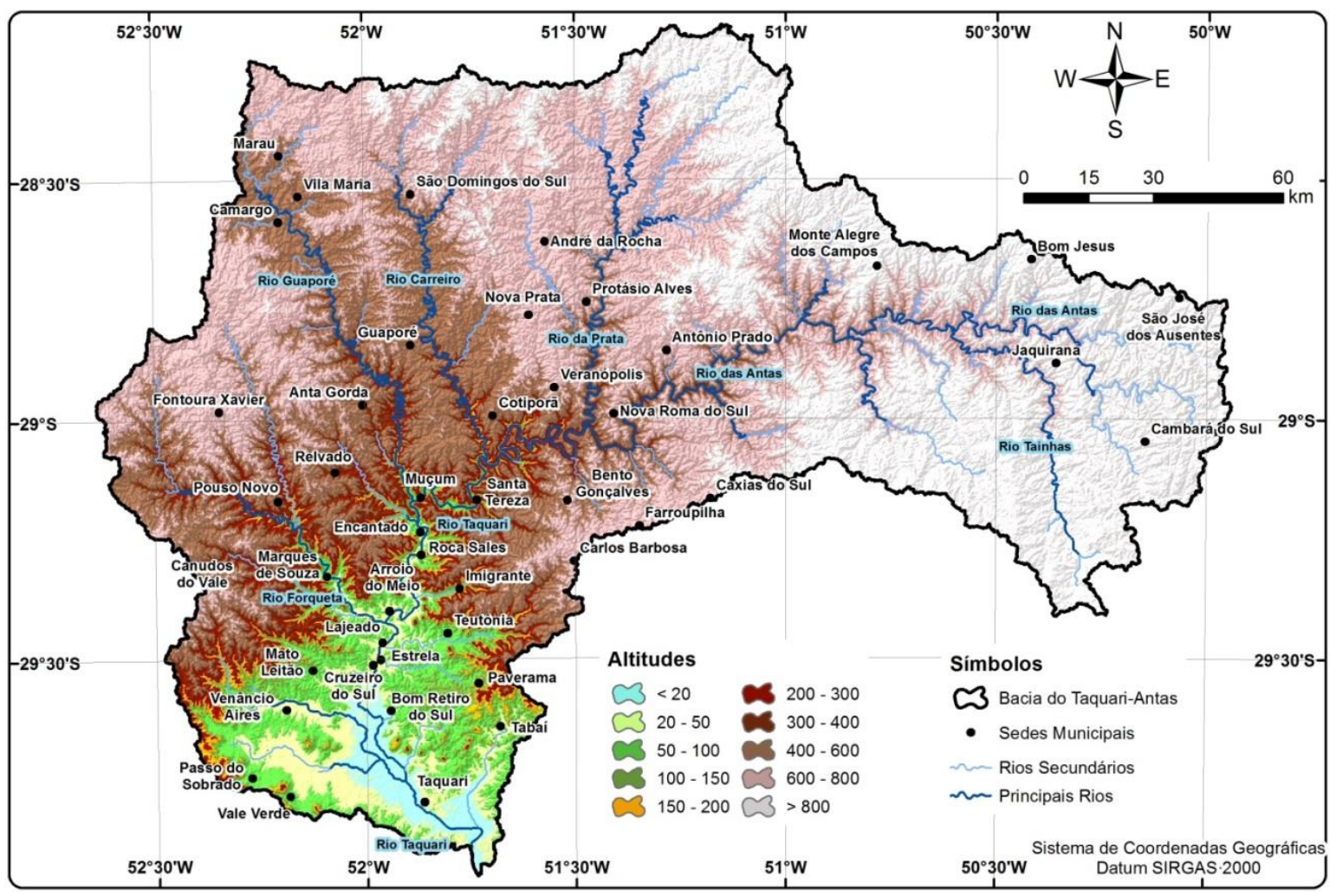

Figura 1 - Mapa de localização da Bacia Hidrográfica do Rio Taquari-Antas, RS.

$\mathrm{Na}$ bacia do rio Taquari-Antas ocorrem processos hidrológicos extremos e distintos: no vale do rio Taquari predominam as inundações graduais, com aumento de nível do rio na ordem de centímetros por hora, em virtude da grande área de drenagem; nos afluentes do rio Taquari, como o Forqueta, o Guaporé e o Carreiro, por outro lado, predominam as enxurradas, com aumento de nível na ordem de metros por hora, em virtude da menor dimensão destas sub-bacias e a consequente redu- 
ção no tempo de concentração (Ferri \& Togni, 2012). No segundo caso, a prevenção e o alerta dificilmente podem ser realizados com antecedência, o que dificulta a ação da Defesa Civil.

Por outro lado, as águas voltam ao nível normal de forma mais rápida, o que agiliza o processo de reestruturação pós-desastre. Os prejuízos e as perdas materiais são mais concentrados no espaço, visto que os eventos atingem áreas menores, porém mais intensos devido à velocidade do processo, podendo inclusive ocasionar perdas humanas.

A modelagem e o mapeamento das áreas suscetíveis às inundações e enxurradas são medidas essenciais para o planejamento de municípios que se desenvolvem junto aos fundos de vales. Essas medidas podem amenizar os danos decorrentes das inundações, seja em função de um reordenamento e redirecionamento da expansão das cidades ou em decorrência de novas estratégias para a atuação da Defesa Civil.
Considerando a importância do tema e a necessidade de aprofundar os conhecimentos relacionados às inundações e enxurradas em escala regional, o objetivo deste estudo foi mapear e caracterizar as áreas suscetíveis a inundações e enxurradas na bacia do rio Taquari-Antas. Em virtude da extensa área de estudo, com mais de $26.000 \mathrm{~km}^{2}$, a proposta desse estudo é fazer uma adaptação dos métodos apresentados em Rennó et al. (2008) e Oliveira (2010) para caracterização da suscetibilidade às inundações em escala regional. Utilizando a mesma abordagem, de simular as áreas inundáveis acima das linhas de drenagem (como o modelo Height Above Nearest Drainage - HAND), neste estudo, a adaptação se refere principalmente em analisar séries hidrológicas históricas distribuídas na bacia para projetar um aumento de nível de acordo com a frequência registrada na série histórica, não adotando um mesmo valor para todas as linhas de drenagem.

\section{METODOLOGIA}

A metodologia para mapeamento e caracterização das inundações e enxurradas na bacia hidrográfica do rio Taquari-Antas foi baseada nos estudos de Rennó et al. (2008) e Oliveira (2010). Entretanto, a proposta do presente estudo promove uma adaptação dos métodos, aprofundando na elaboração de índices hidrológicos, tais como o tempo de concentração e o cálculo de vazões e níveis fluviais máximos em função do tempo de retorno (TR).

Foram utilizados dados Shuttle Radar Topography Mission (SRTM) para a modelagem digital da elevação (MDE) visando à delimitação da bacia hidrográfica e da hidrografia e a estimativa de índices morfométricos e hidrológicos. Para validar alguns índices, foram consultados dados hidrológicos disponíveis para a área da bacia, bem como materiais cartográficos e temáticos provenientes de estudos prévios. O mapeamento das áreas suscetíveis a inundações e enxurradas foi realizado por meio da simulação do aumento do nível da água em cada segmento de rio, em função do MDE. Duas expedições a campo foram realizadas tanto para validação quanto para caracterização dos processos hidrológicos que ocorrem na bacia.

\section{Identificação das linhas de drenagem e da bacia hidrográfica}

Os dados obtidos por sensoriamento remoto da missão SRTM estão vastamente difundidos e possuem aplicações no âmbito de diagnósticos ambientais e de estudos relacionados às dinâmicas geomorfológicas e hidrológicas (Valeriano, 2008; Paz \& Collischonn, 2008). Tais dados configuram-se como uma alternativa importante na diminuição de custos e do tempo na produção de estudos no âmbito da análise ambiental, uma vez que possibilitam, de forma rápida e eficiente, a extração de redes de drenagem e a análise morfométrica do terreno a partir de geoprocessamento.

A base de dados altimétricos utilizada foi a SRTM, disponível em uma versão refinada para o território brasileiro por meio do TOPODATA Banco de Dados Geomorfométricos do Brasil (Valeriano, 2008). As informações altimétricas foram adquiridas em formato raster, com resolução espacial aproximada de $30 \mathrm{~m}$. As principais justificativas para a utilização deste material se referem à qualidade dos dados para representar o terreno em escalas intermediárias (de 1:100.000 a 1:250.000), à acessibilidade e à gratuidade, que garantem que a mesma metodologia possa ser reproduzida em outras 
bacias hidrográficas ou regiões do Brasil.

Para a delimitação da bacia hidrográfica do rio Taquari-Antas foi adotado um procedimento automatizado, por meio do software ArcGIS 10.3. O processo de extração de drenagem utiliza como base a informação de direção de fluxo (Flow Direction), derivada da camada de altimetria extraída dos dados SRTM. A partir da base de direções de fluxo é gerada uma imagem com as áreas de drenagem acumuladas (Flow Accumulation), em que cada pixel tem um valor correspondente ao somatório das áreas superficiais de todos os pixels que deságuam nele (Paz \& Collischonn, 2008; Jenson \& Domingue, 1988). O plano de informações de áreas de drenagem acumuladas, juntamente das direções de fluxo, é utilizado na delimitação da bacia e das linhas de drenagem. Como limiar para considerar o início da hidrografia (localização das nascentes), foi utilizado um valor de $1 \mathrm{~km}^{2}$ para área de drenagem acumulada. Este valor gera uma densidade de nascentes semelhante à cartografia na escala 1:50.000 da Divisão de Serviços Geográficos do Exército (DSG), vetorizada por Hasenack \& Weber (2010).

\section{Estimativa de índices morfométricos e hidrológicos}

Após identificação da bacia hidrográfica e da hidrografia, foi realizada a estimativa dos seguintes índices morfométricos e hidrológicos para cada segmento de linha de drenagem: i) área de drenagem acumulada (A); ii) comprimento de drenagem acumulado desde a nascente mais distante (L); iii) declividade média da drenagem principal a montante (S); iv) tempo de concentração (tc); v) vazão média diária máxima anual (Qmax) e vazões máximas em TRs de 5, 10, 20, 50 e 100 anos (Qmax5, Qmax10, Qmax20, Qmax50 e Qmax 100).

A obtenção da área de drenagem acumulada (A) já foi mencionada na etapa anterior, pois se trata de um pré-requisito para a delimitação da bacia. O comprimento de drenagem acumulado desde a nascente mais distante (L) foi obtido por meio da ferramenta Flow Lenght, no modo Upstream. Nesta função é realizado o cálculo da distância pela drenagem de cada ponto em relação à nascente mais distante.

Para o cálculo da declividade média de cada linha de drenagem a montante (S) não há uma ferramenta disponível nos principais Sistemas de Informações Geográficas, sejam comerciais ou gratuitos. Assim, foi necessário realizar um procedimento semiautomático que consistiu em: i) localizar as nascentes, ii) identificar qual é a nascente mais distante para cada linha de drenagem, iii) obter a altimetria nas nascentes e em cada vértice da linha de drenagem e, iv) calcular a declividade média a montante.

A localização das nascentes pode ser realizada automaticamente, bastando converter as linhas de drenagem de primeira ordem para o formato de pontos, considerando apenas o vértice inicial. Isso pode ser realizado na função Feature Vertices to Points do software ArcGIS 10.3. Já para associar cada segmento da hidrografia à sua nascente mais distante foi realizado um processo manual, de montante a jusante, nas hidrografias de $2^{\mathrm{a}}$ ordem em diante, até que cada segmento de drenagem na bacia tenha um campo na tabela de atributos indicando qual é a sua nascente (por meio de um código identificador).

Uma vez que a hidrografia estava com a tabela de atributos associada por meio de um código identificador à tabela de nascentes, foi possível extrair os valores altimétricos (Extract Values to Points) provenientes da base SRTM-TOPODATA tanto para as nascentes quanto para cada vértice das linhas de hidrografia. A partir disso, pode-se calcular para cada vértice das linhas de drenagem o valor de $S$, tendo como referência a Equação 1:

$$
S_{i}=\frac{Z_{n}-Z_{i}}{L_{i}}
$$

Em que: $S_{i}$ é a declividade média da drenagem principal a montante no pixel $i ; Z_{n}$ é a altitude da nascente $n$ relacionada ao pixel $i ; Z_{i}$ é a altitude do pixel $i ; L_{i}$ é o comprimento de drenagem acumulado desde a nascente $n$ até o pixel $i$.

O tempo de concentração (tc) é o intervalo de tempo necessário para que toda a área da bacia contribua para o escoamento superficial na foz (TUCCI, 2014). Quanto ao cálculo do tc, tendo em vista a diversidade de equações para a estimativa deste índice, optou-se por testar a aplicação de cinco diferentes metodologias, aplicáveis em bacias de diferentes dimensões, utilizando-se como variáveis de entrada apenas os valores de A, LeS.

Os métodos testados foram os seguintes: i) Dooge (Equação 2); ii) Johnstone (Equação 3); iii) Corps of Engineers (Equação 4); iv) Kirpich (Equação 5); v) Ven te Chow (Equação 6). Estas equações foram consultadas no estudo de Silveira (2005). 


$$
\begin{aligned}
& t c=0,365 A^{0,41} S^{-0,17} \\
& t c=0,462 L^{0,5} S^{-0,25} \\
& t c=0,191 L^{0,76} S^{-0,19} \\
& t c=0,0663 L^{0,77} S^{-0,385} \\
& t c=0,16 L^{0,64} S^{-0,32}
\end{aligned}
$$

A validação para selecionar o método mais eficiente para a estimativa do tempo de concentração foi realizada por meio da análise de dados horários de cotas (cotagramas) das estações fluviométricas de Estrela (Rio Taquari), do Forqueta e de Marques de Souza (Rio Forqueta) e do Rio das Antas, disponibilizados pelo Centro de Informações Hidrometeorológicas (CIH), do Centro Universitário UNIVATES, por meio do website http://netsenses.univates.br/. Para identificar o fim da precipitação, consideraram-se as estações pluviométricas de Fontoura Xavier e Monte Alegre dos Campos (CIH-Univates), Soledade e São José dos Ausentes (Instituto Nacional de Meteorologia - INMET). O procedimento adotado para a identificação do fim do escoamento superficial é o descrito por Chow, Maidment e Mays (1994). Além disso, foi consultado como referência bibliográfica o estudo de Kurek (2016) que analisou cotagramas diários em algumas estações fluviométricas do Vale do Taquari.

Quanto à estimativa da vazão média diária máxima anual (Qmax) e das vazões máximas em TRs de 5, 10, 20, 50 e 100 anos (Qmax5, Qmax10, Qmax20, Qmax50 e Qmax100), o procedimento adotado consiste na regionalização de vazões máximas na bacia.

Nesta etapa, foi adotado o procedimento metodológico sugerido por Tucci (2014), que consiste nos seguintes passos:

i) Escolha dos postos fluviométricos e suas respectivas séries hidrológicas em função da disponibilidade e consistência dos dados: foram utilizadas as séries hidrológicas listadas na Tabela 1, obtidas no portal Hidroweb da Agência Nacional de Águas (ANA);

ii) Cálculo da vazão média diária máxima anual (Qmax) para cada estação fluviométrica escolhida: foi identificada a maior vazão diária em cada ano hidrológico para todas as estações selecionadas. $\mathrm{O}$ ano hidrológico foi considerado de abril a março, tendo em vista que os meses de março e abril normalmente são os mais secos, quando predominam as estiagens;

iii) Cálculo da vazão adimensional para as séries de máximos anuais para cada estação fluviométrica: uma vez que as séries utilizadas se referem a estações fluviométricas instaladas em rios com muita diferença de área de drenagem e vazão, é necessário transformar os valores de vazão, dividindo-se a vazão máxima anual pela vazão média diária máxima anual (Qmax);

iv) Ajuste de distribuições estatísticas para os valores extremos: o ajuste de distribuições estatísticas é necessário para estimar os valores adimensionais de vazão para os TRs de 5, 10, 20, 50 e 100 anos. Foram testadas as distribuições GEV, Gama, Gumbel e Log-Pearson Tipo III. O teste de aderência foi o de Kolmogorov-Smirnov, a um nível de significância de 0,05 ;

v) Definição de uma curva regional, conforme a tendência observada após os ajustes estatísticos realizados às séries adimensionais em cada estação fluviométrica: optou-se por calcular o valor médio adimensional para cada TR, considerando todas as séries hidrológicas;

vi) Estimativa da vazão média diária máxima anual (Qmax) em função da área de drenagem (A), por meio de uma regressão: foi realizado o ajuste de um modelo de regressão, buscando relacionar os valores de Qmax em função de A, para estimar a vazão média diária máxima anual para qualquer ponto da bacia com área conhecida. Foram testadas funções da biblioteca dos softwares MatLab e LabFit;

vii) Estimativa dos valores de vazão máxima em TRs de 5, 10, 20, 50 e 100 anos (Qmax5, Qmax10, Qmax20, Qmax50 e Qmax100): a partir dos valores de Qmax obtidos por meio da equação ajustada no passo anterior (vi) e dos valores de vazão adimensionais obtidos na curva regional (v), é possível estimar a vazão para diferentes TRs em qualquer ponto da bacia hidrográfica com área conhecida.

\section{Caracterização das áreas suscetíveis a inundações e enxurradas}

Nesta etapa, foram realizados o mapeamento e a caracterização das áreas suscetíveis a inundações e enxurradas na bacia do Taquari-Antas. Foram consultadas todas as séries hidrológicas de cotas disponíveis no portal Hidroweb da ANA para analisar o aumento do nível do rio em relação à cota média histórica.

Além disso, foi consultada a base cartográfica geomorfológica da bacia, atualizada em Oliveira et al. (2015), para auxiliar na caracterização das áreas suscetíveis. Também foram realizadas duas expedições a campo tanto para validação quanto para caracterização dos processos hidrológicos 
que ocorrem na bacia. As áreas urbanas atingidas por eventos hidrológicos, visitadas nas expedições, foram nas cidades de: Taquari, Vila Mariante (dis- trito de Venâncio Aires), Venâncio Aires, Cruzeiro do Sul, Lajeado, Estrela, Arroio do Meio, Marques de Souza, Encantado, Muçum e Santa Tereza.

Tabela 1 - Séries hidrológicas do Hidroweb (ANA) utilizadas na regionalização das vazões máximas na bacia do rio Taquari-Antas.

\begin{tabular}{c|c|c|c}
\hline Código & Nome da Estação & Área de Drenagem $\mathbf{( k m}^{\mathbf{2}}$ & Período \\
\hline $\mathbf{8 6 1 0 0 0 0 0}$ & Passo do Gabriel & 1.820 & $1940-2006$ \\
\hline $\mathbf{8 6 1 6 0 0 0 0}$ & Passo Tainhas & 1.120 & $1940-2006$ \\
\hline $\mathbf{8 6 4 1 0 0 0 0}$ & Passo Barra do Guaiaveira & 2.820 & $1956-2006$ \\
\hline $\mathbf{8 6 4 2 0 0 0 0}$ & Ponte do Prata & 317 & $1959-2006$ \\
\hline $\mathbf{8 6 4 8 0 0 0 0}$ & Passo Migliavaca & 1.330 & $1956-2006$ \\
\hline $\mathbf{8 6 5 0 0 0 0 0}$ & Passo Carreiro & 1.820 & $1939-2006$ \\
\hline $\mathbf{8 6 5 1 0 0 0 0}$ & Muçum & 16.000 & $1940-2006$ \\
\hline $\mathbf{8 6 5 6 0 0 0 0}$ & Linha Colombo & 2.030 & $1939-2006$ \\
\hline $\mathbf{8 6 5 8 0 0 0 0}$ & Santa Lúcia & 2.470 & $1940-2006$ \\
\hline $\mathbf{8 6 7 0 0 0 0 0}$ & Ponte Jacaré & 436 & $1943-2006$ \\
\hline $\mathbf{8 6 7 2 0 0 0 0}$ & Encantado & 19.100 & $1941-2006$ \\
\hline $\mathbf{8 6 7 4 5 0 0 0}$ & Passo do Coimbra & 791 & $1957-2006$ \\
\hline
\end{tabular}

Após a análise de todos os dados disponíveis, foram definidos os critérios e os procedimentos para a delimitação de áreas suscetíveis. Optou-se por demarcar essas áreas em função do aumento do nível dos rios observado nas séries históricas. Uma vez que são conhecidas as altitudes de cada segmento de hidrografia e também a altura atingida pelas águas em locais com estações fluviométricas, é possível também estimar a cota altimétrica atingida pelas águas.

O mapeamento foi dividido em duas classes: i) áreas atingidas de modo frequente; ii) áreas atingidas de modo remoto. Na primeira classe foi considerado o valor frequentemente atingido pelas águas em cada estação fluviométrica, em TR de aproximadamente 5 anos. Na segunda classe foi considerado o maior valor de nível registrado em cada estação fluviométrica.

Com base nessas condições, o mapeamento foi realizado por meio de técnicas de geoprocessamento, utilizando-se como MDE a base de dados SRTM-TOPODATA. Em seguida, as cotas de inundações e enxurradas (frequentes ou remotas) foram interpoladas, pelo método do inverso da distância ao quadrado, ao longo dos principais cursos d'água, considerando somente os segmentos com área de drenagem igual ou maior que $20 \mathrm{~km}^{2}$ e em altitudes inferiores a 800 metros, limiar que demarca os limites entre a Serra Geral (áreas com ocorrências de enxur-radas) e os Campos Gerais (áreas mais altas da bacia).

$\mathrm{O}$ mapeamento final foi obtido utilizando a ferramenta "Raster Calculator" do ArcGIS 10.3, subtraindo a base de cotas atingidas pela base altimétrica, o que gera uma mancha de inundação. Na Tabela 2 são apresentados os critérios utilizados para a delimitação das áreas com ocorrência de inundações e enxurradas frequentes e remotas (raras). Os valores apresentados são aproximados e se baseiam na análise dos dados de cotas e os relatos e registros obtidos a campo.

A caracterização das áreas suscetíveis em relação ao tipo de evento (inundações ou enxurradas) foi realizada em pontos de interesse ao longo dos principais rios, em função dos índices obtidos na etapa anterior, e também em função de aspectos geomorfológicos observados na base cartográfica de geomorfologia e nas expedições a campo. Também foram identificados e quantificados os municípios mais atingidos (malha municipal obtida junto ao IBGE), as áreas urbanas (desenhadas no Google Earth) sobrepostas às áreas suscetíveis e os tipos de uso e ocupação da terra (base digital obtida junto ao IBGE).

\section{RESULTADOS E DISCUSSÕES}

A figura 2 ilustra a subdivisão em sub-bacias e seus respectivos valores de área de drenagem (A), comprimento do rio principal desde a nascente (L), declividade média do rio principal
(S), tempo de concentração (tc), vazão média diária máxima anual (Qmax) e vazões máximas em TRs de 5, 10, 20, 50 e 100 anos (Qmax5, Qmax10, Qmax20, Qmax50 e Qmax100). 
Tabela 2 - Aumento no nível do rio (m) utilizados para o mapeamento das áreas suscetíveis a inundações e enxurradas na bacia do rio Taquari-Antas.

\begin{tabular}{|c|c|c|c|}
\hline \multirow[b]{2}{*}{ Rios } & \multirow[b]{2}{*}{ Municípios } & \multicolumn{2}{|c|}{ Aumento no nível do rio (m) } \\
\hline & & $\begin{array}{c}\text { Frequente } \\
(\mathrm{TR}=5 \text { anos })\end{array}$ & $\begin{array}{c}\text { Remoto } \\
\text { (Maior cheia) }\end{array}$ \\
\hline \multirow{6}{*}{ Taquari } & Taquari & 7 & 14 \\
\hline & Vila Mariante (Venâncio Aires) & 7 & 15 \\
\hline & Bom Retiro do Sul & 8 & 16 \\
\hline & Cruzeiro do Sul, Lajeado e Estrela & 9 & 17 \\
\hline & Arroio do Meio e Santa Tereza & 9 & 17 \\
\hline & Roca Sales, Encantado e Muçum & 10 & 18 \\
\hline \multirow{4}{*}{ Antas } & Veranópolis e Bento Gonçalves & 9 & 17 \\
\hline & Pinto Bandeira e Antônio Prado & 8 & 16 \\
\hline & Caxias do Sul e Monte Alegre dos Campos & 6 & 12 \\
\hline & Bom Jesus e Jaquirana & 5 & 10 \\
\hline \multirow{3}{*}{ Prata } & Veranópolis e Nova Roma do Sul & 6 & 12 \\
\hline & Antônio Prado e Protásio Alves & 5 & 10 \\
\hline & André da Rocha e Guabiju & 4 & 8 \\
\hline \multirow{3}{*}{ Forqueta } & Lajeado e Arroio do Meio & 6 & 12 \\
\hline & Marques de Souza e Travesseiro & 5 & 10 \\
\hline & Pouso Novo e Fontoura Xavier & 4 & 8 \\
\hline \multirow{3}{*}{ Carreiro } & São Valentin do Sul/Cotiporã & 6 & 12 \\
\hline & Guaporé/Vista Alegre do Prata & 5 & 10 \\
\hline & Nova Bassano e São Domingos do Sul & 4 & 8 \\
\hline \multirow{3}{*}{ Guaporé } & Encantado/Muçum & 6 & 12 \\
\hline & Anta Gorda/Guaporé & 5 & 10 \\
\hline & Montauri e Vila Maria & 4 & 8 \\
\hline Tainhas & São Francisco de Paula e Jaquirana & 4 & 8 \\
\hline \multirow{2}{*}{ Fão } & Pouso Novo e Marques de Souza & 5 & 10 \\
\hline & Barros Cassal e Fontoura Xavier & 4 & 8 \\
\hline Telha & Muitos Capões e Ipê & 4 & 8 \\
\hline Turvo & Muitos Capões e André da Rocha & 4 & 8 \\
\hline Lajeado Grande & São Francisco de Paula e Caxias do Sul & 4 & 8 \\
\hline Refugiado & Vacaria & 4 & 8 \\
\hline Camisas & Cambará do Sul e Jaquirana & 4 & 8 \\
\hline São Domingos & Casca e São Domingos do Sul & 4 & 8 \\
\hline Taquari-Mirim & Venâncio Aires e Vale Verde & 5 & 10 \\
\hline \multirow{2}{*}{ Arroio Boa Vista } & Foz (Estrela) & 5 & 10 \\
\hline & Teutônia & 4 & 8 \\
\hline \multirow{2}{*}{ Arroio Castelhano } & Venâncio Aires & 5 & 10 \\
\hline & Monte Alverne (Santa Cruz do Sul) & 4 & 7 \\
\hline Arroio Jacaré & Encantado & 5 & 9 \\
\hline Arroio Forquetinha & Forquetinha & 5 & 10 \\
\hline \multirow{2}{*}{ Arroio Santa Cruz } & Taquari e Triunfo & 5 & 10 \\
\hline & Tabaí & 4 & 8 \\
\hline Arroio São Tomé & São Francisco de Paula & 4 & 8 \\
\hline \multirow{2}{*}{ Arroio Estrela } & Foz (Estrela) & 5 & 10 \\
\hline & Teutônia & 4 & 8 \\
\hline Arroio Marau & Marau & 4 & 7 \\
\hline Arroio Capivara & Taquari & 4 & 7 \\
\hline \multirow{2}{*}{ Arroio Bonito } & Venâncio Aires e Cruzeiro do Sul & 4 & 8 \\
\hline & Mato Leitão & 3 & 6 \\
\hline Arroio do Potreiro & Taquari & 4 & 7 \\
\hline Demais arroios & - & 3 & 6 \\
\hline
\end{tabular}




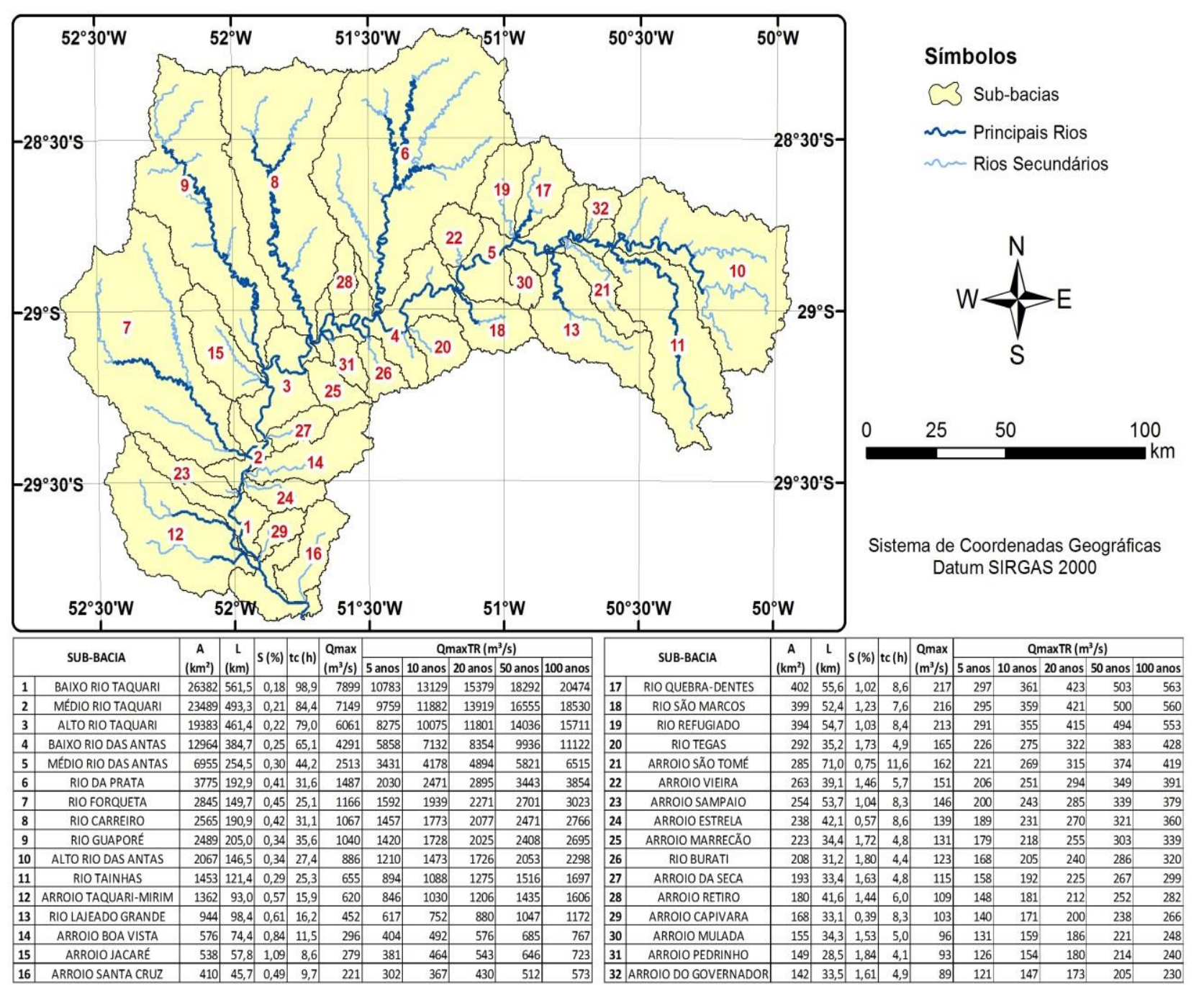

Figura 2 - Índices hidrológicos nas sub-bacias Taquari-Antas.

Em relação à área de drenagem acumulada (A), além do rio Taquari $\left(26.382 \mathrm{~km}^{2}\right)$ e do rio das Antas (12.964 $\mathrm{km}^{2}$ ), que representam a principal linha de drenagem da bacia, outros afluentes se destacam em tamanho: rio da Prata $\left(3.775 \mathrm{~km}^{2}\right)$, rio Forqueta $\left(2.845 \mathrm{~km}^{2}\right)$, rio Carreiro $\left(2.565 \mathrm{~km}^{2}\right)$ e rio Guaporé $\left(2.489 \mathrm{~km}^{2}\right)$. Estas quatro sub-bacias possuem dimensões relativamente semelhantes, o que indica uma contribuição significativa em termos de volume de água e, possivelmente, que suas águas chegam ao rio principal em intervalo de tempo próximo, o que favorece a ocorrência de variações abruptas na vazão do rio Taquari-Antas.

Considerando o índice de comprimento do rio desde a nascente mais distante (L), o destaque é para o rio das Antas, que possui uma extensão de $384,7 \mathrm{~km}$. Somando-se ao rio Taquari, o canal principal possui $561,5 \mathrm{~km}$. Os principais afluentes são o rio Guaporé $(205 \mathrm{~km})$, o rio da Prata $(193 \mathrm{~km})$ e o rio Carreiro $(191 \mathrm{~km})$. O rio Guaporé (Bacia 9), embora tenha uma área de drenagem inferior aos rios da Prata (Bacia 6), Forqueta (Bacia 7) e Carreiro (Bacia 8), possui uma forma mais alongada, com o rio repleto de curvas e cotovelos, escoando por uma linha central na bacia, o que favorece a maior extensão do rio em relação às bacias vizinhas.

Quanto à declividade média do rio principal (S), destacam-se as bacias menores, com rios de comprimentos inferiores e amplitude altimétrica considerável, principalmente na porção central e montante da bacia: Arroio Pedrinho (Bacia 31), Rio Burati (Bacia 26), Rio Tegas (Bacia 20), Arroio Marrecão (Bacia 25), com declividade do rio variando entre $1,72 \%$ e $1,84 \%$. O rio TaquariAntas possui uma declividade média de $0,18 \%$, sendo que as maiores declividades no rio são observadas nos trechos referentes ao Alto e Médio Rio das Antas.

Os valores de tempo de concentração (tc) apresentados na Figura 2 foram obtidos por meio do método de Kirpich (Equação 5). A escolha desse método se deve ao melhor ajuste em 
relação aos cotagramas observados em três das quatro seções analisadas.

O primeiro cotagrama analisado se refere à seção da estação de Estrela, localizada no rio Taquari junto ao Porto de Estrela. Nesta seção, utilizando-se dados horários disponibilizados pelo CIH-Univates foram analisadas três cheias: i) $06 / 06 / 2014$; ii) $29 / 06 / 2014$; iii) 20/10/2014. Nesta seção do rio, o método que apresentou resultados mais consistentes (Tabela 3) foi o de Ven te Chow, com erro médio de $4,3 \%$.

Tabela 3 - Tempo de concentração (tc) no Porto de Estrela, rio Taquari.

\begin{tabular}{|c|c|c|c|c|c|c|c|c|c|c|c|}
\hline Evento & \multicolumn{2}{|c|}{ Fim da Chuva } & \multicolumn{2}{|c|}{$\begin{array}{c}\text { Fim do } \\
\text { Escoamento } \\
\text { Superficial } \\
\end{array}$} & \multirow{2}{*}{$\begin{array}{l}\text { tc (h) } \\
54,50 \\
\end{array}$} & $\begin{array}{l}\text { Kurek } \\
(2016)\end{array}$ & Dooge & Johnstone & $\begin{array}{c}\text { Corp. } \\
\text { Engineers }\end{array}$ & Kirpich & $\begin{array}{l}\text { Ven te } \\
\text { Chow }\end{array}$ \\
\hline 1 & $05 / 06 / 14$ & $18: 45$ & 08/06/14 & $01: 15$ & & \multirow{3}{*}{72} & \multirow{3}{*}{64,2} & \multirow{3}{*}{47,7} & \multirow{3}{*}{67,9} & \multirow{3}{*}{83,6} & \multirow{3}{*}{60,4} \\
\hline 2 & $29 / 06 / 14$ & $06: 15$ & $01 / 07 / 14$ & $17: 00$ & 58,75 & & & & & & \\
\hline 3 & $19 / 10 / 14$ & 10:00 & $21 / 10 / 14$ & $22: 30$ & 60,50 & & & & & & \\
\hline \multicolumn{5}{|c|}{ Média e Erro Médio (\%) } & 58 & - & $10,8 \%$ & $-17,6 \%$ & $17,2 \%$ & $44,3 \%$ & $4,3 \%$ \\
\hline
\end{tabular}

$\mathrm{O}$ segundo cotagrama analisado se refere à seção da estação fluviométrica de Marques de Souza, localizada no rio Forqueta. Nesta seção, utilizando-se dados horários disponibilizados pelo CIH-Univates foram analisadas quatro cheias: i) $06 / 06 / 2014$; ii) $30 / 06 / 2014$; iii) $24 / 07 / 2014$; iv) 20/10/2014. Pode-se observar na Tabela 4 que o método que apresentou resultados mais consistentes nesta seção foi o de
Kirpich, com erro médio de -25,7\%.

$\mathrm{O}$ terceiro cotagrama analisado se refere à seção da estação fluviométrica do Forqueta, localizada em Arroio do Meio, no rio Forqueta. Nesta seção foram analisadas duas cheias: i) 06/06/2014; ii) 20/10/2014. De acordo com os resultados obtidos (Tabela 5), o método que apresentou maior consistência foi o de Kirpich, com erro médio de $-49,9 \%$.

Tabela 4 - Tempo de concentração (tc) em Marques de Souza, rio Forqueta.

\begin{tabular}{|c|c|c|c|c|c|c|c|c|c|c|c|}
\hline Evento & Fim da $C$ & huva & $\begin{array}{c}\text { Fim } \\
\text { Escoam } \\
\text { Superf }\end{array}$ & $\begin{array}{l}\text { o } \\
\text { ento } \\
\text { cial }\end{array}$ & tc (h) & $\begin{array}{c}\text { Kurek } \\
(2016)\end{array}$ & Dooge & Johnstone & $\begin{array}{c}\text { Corp. } \\
\text { Engineers }\end{array}$ & Kirpich & $\begin{array}{l}\text { Ven te } \\
\text { Chow }\end{array}$ \\
\hline 1 & 05/06/14 & 19:00 & 07/06/14 & 00:00 & 29,00 & & \multirow{4}{*}{21,1} & \multirow{4}{*}{19,7} & \multirow{4}{*}{21,0} & \multirow{4}{*}{21,4} & \multirow{4}{*}{19,5} \\
\hline 2 & $30 / 06 / 14$ & 03:45 & $01 / 07 / 14$ & $03: 15$ & 23,50 & & & & & & \\
\hline 3 & $24 / 07 / 14$ & $21: 45$ & $25 / 07 / 14$ & 23:00 & 25,25 & & & & & & \\
\hline 4 & $19 / 10 / 14$ & 12:00 & $21 / 10 / 14$ & $01: 30$ & 37,50 & & & & & & \\
\hline \multicolumn{5}{|c|}{ Média e Erro Médio (\%) } & 29 & - & $-26,8 \%$ & $-31,6 \%$ & $-27,1 \%$ & $-25,7 \%$ & $-32,3 \%$ \\
\hline
\end{tabular}

Tabela 5 - Tempo de concentração no rio Forqueta, em Arroio do Meio.

\begin{tabular}{|c|c|c|c|c|c|c|c|c|c|c|c|}
\hline Evento & \multicolumn{2}{|c|}{ Fim da Chuva } & \multicolumn{2}{|c|}{$\begin{array}{c}\text { Fim do } \\
\text { Escoamento } \\
\text { Superficial } \\
\end{array}$} & \multirow{2}{*}{$\begin{array}{l}\text { tc (h) } \\
51,25 \\
\end{array}$} & \multirow{3}{*}{$\begin{array}{c}\text { Kurek } \\
\text { (2016) } \\
48\end{array}$} & \multirow{3}{*}{\begin{tabular}{|c|} 
Dooge \\
23,8
\end{tabular}} & \multirow{3}{*}{\begin{tabular}{c|} 
Johnstone \\
21,5
\end{tabular}} & \multirow{3}{*}{$\begin{array}{c}\begin{array}{c}\text { Corp. } \\
\text { Engineers }\end{array} \\
23,6\end{array}$} & \multirow{3}{*}{$\begin{array}{c}\text { Kirpich } \\
24,6\end{array}$} & \multirow{3}{*}{$\begin{array}{c}\begin{array}{c}\text { Ven te } \\
\text { Chow }\end{array} \\
21,9\end{array}$} \\
\hline 1 & $05 / 06 / 14$ & 19:00 & $07 / 06 / 14$ & $22: 15$ & & & & & & & \\
\hline 2 & $19 / 10 / 14$ & 12:00 & $21 / 10 / 14$ & 11:00 & 47,00 & & & & & & \\
\hline \multicolumn{5}{|c|}{ Média e Erro Médio (\%) } & 49 & - & $-51,6 \%$ & $-56,2 \%$ & $-52,0 \%$ & $-49,9 \%$ & $-55,4 \%$ \\
\hline
\end{tabular}

$\mathrm{O}$ último cotagrama analisado se refere à seção da estação fluviométrica das Antas, localizada entre os municípios de Bento Gonçalves e Veranópolis, no rio das Antas. Nesta seção foi analisada apenas a cheia do dia 20/10/2014. De acordo com os resultados obtidos, o método que apresentou maior consistência foi o de Kirpich, com erro médio de apenas $0,4 \%$.

É importante destacar que a seção referente à estação fluviométrica do Forqueta está localizada próxima à foz do rio Forqueta, que deságua no rio Taquari, o que justifica as maiores taxas de erro e a dificuldade de estimar o tempo de concentração com as equações testadas. Isso se deve ao fato de haver o represamento das águas do rio Forqueta em períodos de cheias (efeito remanso), retardando a retração do nível do rio e afetando a análise do tempo de concentração. 
Além disso, comparando o tc do rio Forqueta com o do rio Taquari a diferença é de apenas 9 horas, ainda que os índices morfométricos A, L e $\mathrm{S}$ sejam muito distintos. Isso reforça a relativa imprecisão no uso de equações que foram elaboradas em condições muito diferentes das bacias brasileiras.

O estudo de Kurek (2016) também realizou análises em cotagramas para estimar o tempo de concentração em alguns pontos da bacia, porém apenas com dados diários. A autora concluiu que o tempo de concentração do rio Taquari é igual ou superior a três dias, no trecho entre Muçum e o exutório da bacia. Os rios Carreiro, Guaporé, Prata e Forqueta apresentaram um tempo de concentração de dois dias, desaguando praticamente ao mesmo tempo no rio principal.

Considerando também os valores apresentados por Kurek (2016), o método de Kirpich é o que melhor se aproxima dos resultados esperados para o tempo de concentração.

Estes resultados são em parte surpreendentes, já que o método foi proposto para pequenas bacias rurais. No entanto, é importante considerar que outros estudos já confirmaram que a mesma pode ser extrapolada, podendo obter resultados satisfatórios em bacias maiores. Silveira (2005) obteve resultados satisfatórios com o uso das equações de Kirpich e de Ven te Chow para bacias de até $11.162 \mathrm{~km}^{2}$ (erro médio $<10 \%$ ).

É importante mencionar, a partir da análise dos cotagramas, que a equação de Kirpich apresentou uma tendência de superestimar o tempo de concentração em bacias maiores (rio Taquari) e de subestimar os valores em bacias um pouco menores (os afluentes que apresentam represamento das águas em virtude das cheias no rio principal), como foi o caso do rio Forqueta.

Os últimos índices estimados para os segmentos da hidrografia da bacia se referem às vazões máximas (Figura 2), obtidas pelo método de regionalização de vazões. Foram utilizados dados hidrológicos de 12 postos fluviométricos, no período entre 1939 e 2006, com algumas falhas, variando de uma estação para outra. Os anos hidrológicos incompletos foram desconsiderados do cálculo das vazões máximas anuais. A área das bacias no processo de regionalização foi de $317 \mathrm{~km}^{2}$ a $19.100 \mathrm{~km}^{2}$.

A curva regional de vazões adimensionais para a estimativa de vazões máximas na região do Taquari-Antas (Figura 3) indica que, para um TR de 5 anos, a vazão máxima (Qmax5) tende a ser 1,37 vezes maior do que a Qmax (média das vazões máximas anuais). Já para TR de 100 anos (Qmax 100), a vazão máxima tende a ser aproximadamente 2,59 vezes maior do que Qmax.

Para a estimativa de Qmax em cada ponto da bacia, foi utilizada a função apresentada na Figura 4, obtida por uma regressão que calcula a vazão Qmax em função da área de drenagem (A). Este ajuste obteve um resultado satisfatório com um coeficiente de determinação de 0,935 . A escolha dessa função (potência) se deve pelo excelente ajuste observado com uso de apenas dois parâmetros, o que torna o modelo mais parcimonioso.

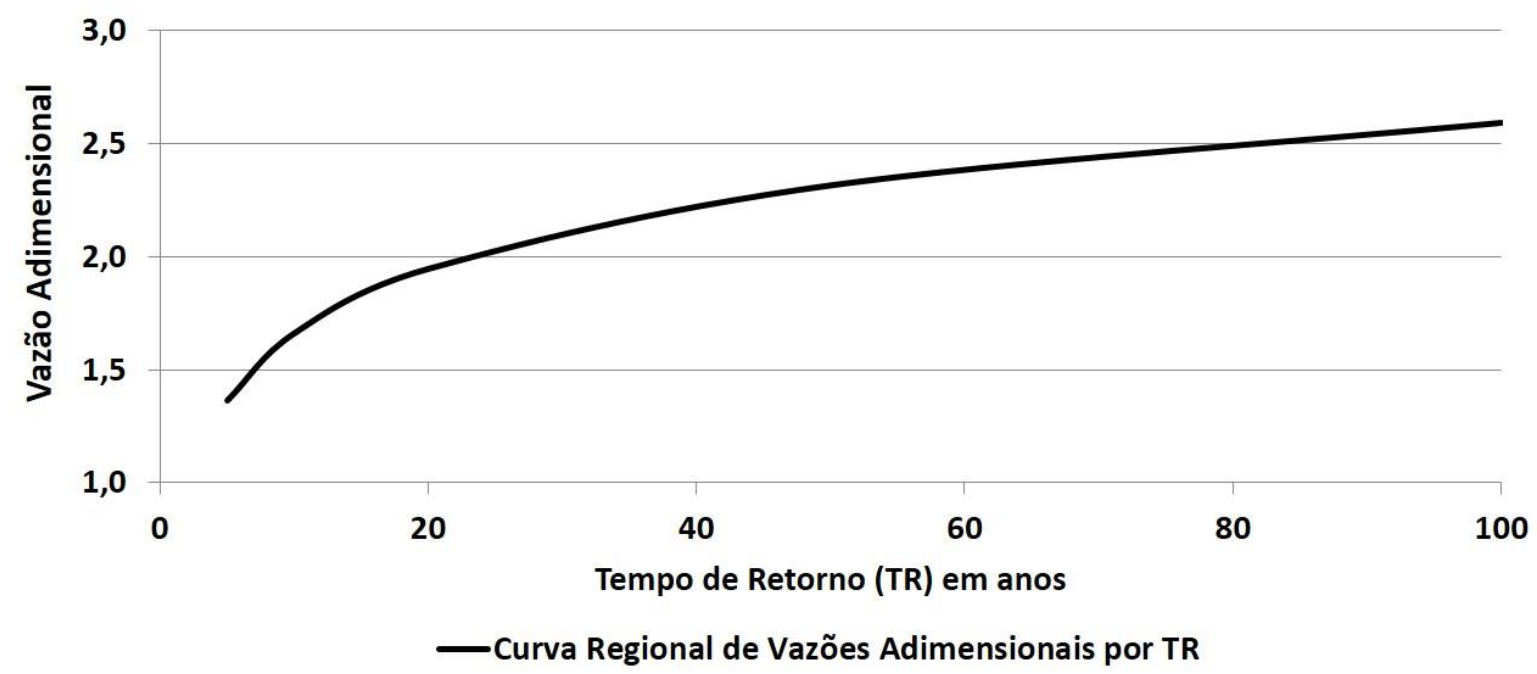

Figura 3 - Curva regional de vazões adimensionais para estimativa de vazão máxima por tempo de retorno, válida para a região do Taquari-Antas, RS. 


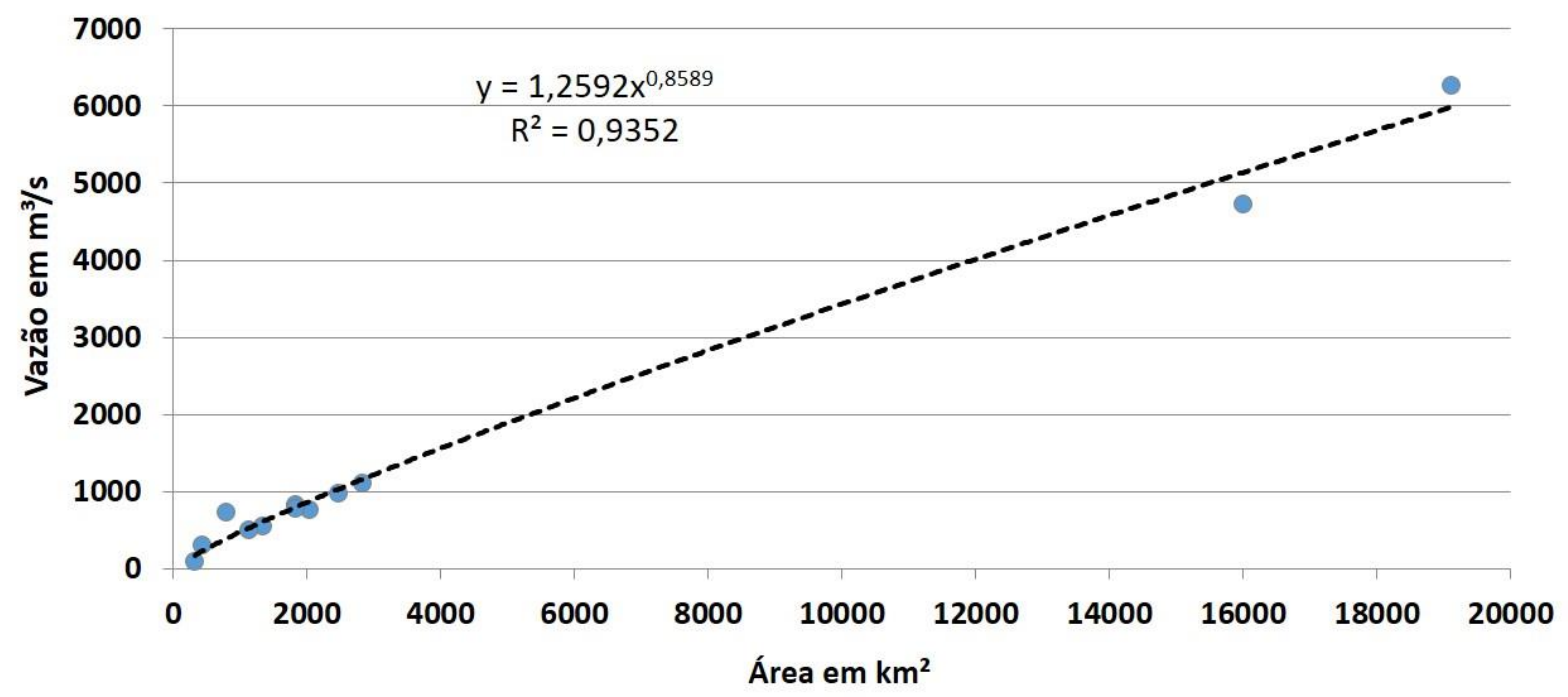

Q Qmax observada $\left(\mathrm{m}^{3} / \mathrm{s}\right)$

----Ajuste por uma função (potência)

Figura 4 - Função para estimativa da vazão média diária máxima anual (Qmax) em função da área da bacia, válida para a região do Taquari-Antas, RS.

A vazão máxima anual (Qmax) do rio Taquari se aproxima de $7.900 \mathrm{~m}^{3} / \mathrm{s}$ no seu trecho final, junto à foz. No rio das Antas, no seu trecho baixo, próximo à confluência do rio Carreiro, os valores de Qmax são de aproximadamente $4.300 \mathrm{~m}^{3} / \mathrm{s}$. Dentre os afluentes do rio Taquari-Antas, se destacam os rios da Prata $\left(\sim 1.490 \mathrm{~m}^{3} / \mathrm{s}\right)$, Forqueta $\left(\sim 1.170 \mathrm{~m}^{3} / \mathrm{s}\right)$, Carreiro $\left(\sim 1.070 \mathrm{~m}^{3} / \mathrm{s}\right)$ e Guaporé $\left(\sim 1.040 \mathrm{~m}^{3} / \mathrm{s}\right)$. Em TRs maiores, referentes às inundações de maior magnitude, a vazão média diária pode ultrapassar $20.000 \mathrm{~m} 3 / \mathrm{s}$ no trecho baixo do rio Taquari.

O mapeamento das áreas suscetíveis a inundações e enxurradas foi realizado tendo como base o aumento do nível dos rios (Tabela 2) verificado nas séries históricas, com apoio de expedições a campo. A Figura 5 ilustra as áreas suscetíveis a esses eventos, bem como alguns pontos de interesse que serão caracterizados nos parágrafos seguintes.

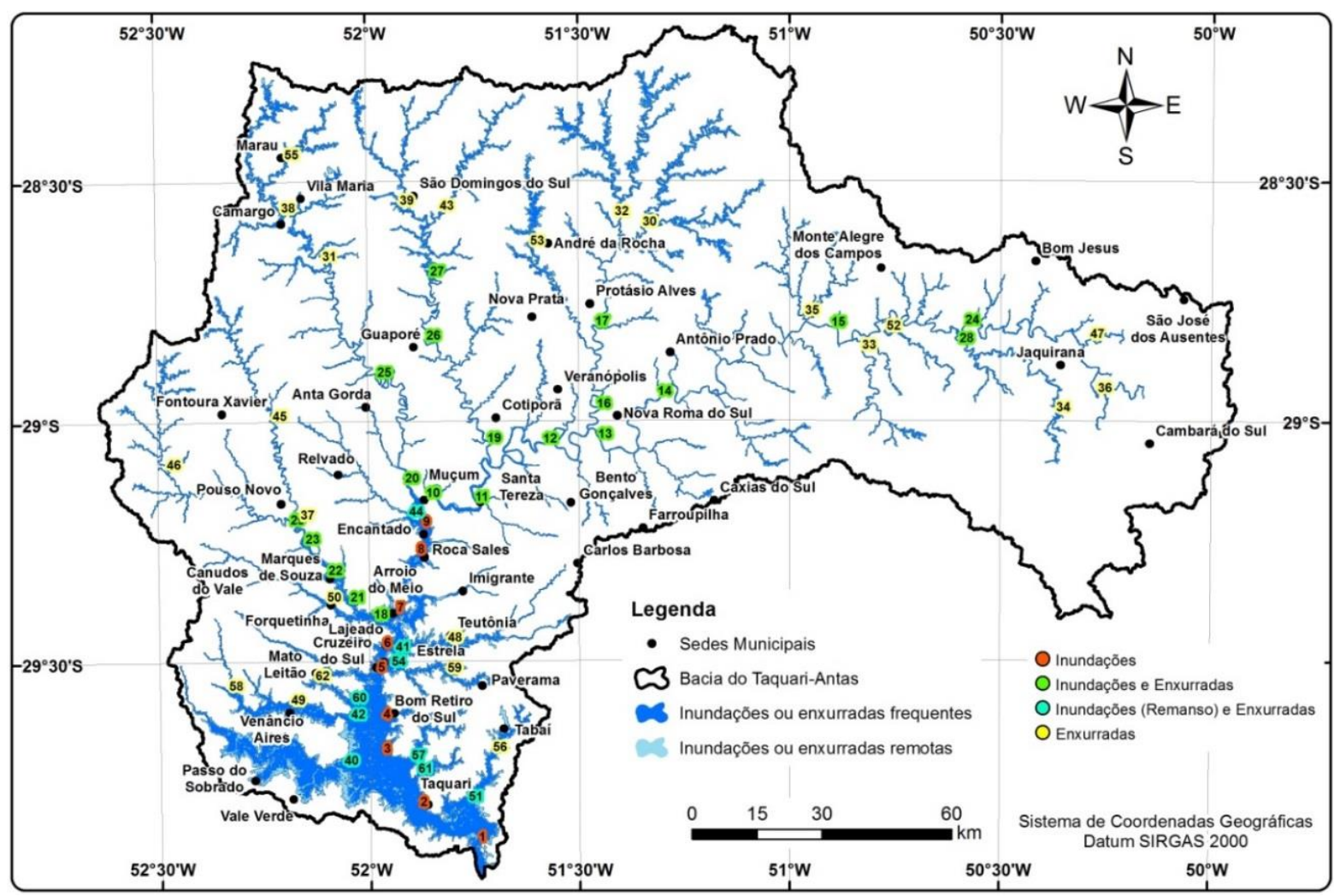

Figura 5 - Áreas suscetíveis a inundações e enxurradas na bacia do Taquari-Antas, RS. 
No rio Taquari, no trecho a jusante de Encantado (entre os pontos 1 e 9 - Figura 5), predominam as inundações. Da foz do rio Taquari, entre Triunfo e General Câmara (Ponto 1), à Encantado (Ponto 9), o rio apresenta $120 \mathrm{~km}$ de extensão. Neste trecho, a resposta hidrológica é lenta e gradual em virtude do comprimento do rio principal ( $>439 \mathrm{~km}$ a partir de Encantado) e da área da drenagem (>19.000 km² a partir de Encantado). Além disso, a declividade do rio se torna pequena, fazendo com que a velocidade do fluxo seja reduzida, favorecendo o acúmulo da água. O tc é igual ou superior a três dias.

No contexto geomorfológico, fica evidente a tendência à ocorrência de inundações mais graduais neste trecho, tendo-se em vista a presença de depósitos sedimentares recentes (terraços e planícies fluviais), com granulometria fina e pouca presença de sedimentos mais grosseiros. Além disso, a largura das planícies onde se depositam os sedimentos carreados pelas águas se torna cada vez maior entre Encantado e Triunfo, geralmente superior a $1 \mathrm{~km}$, superando a $8 \mathrm{~km}$, em Vila Mariante.

Em termos de volume de água, pode-se estimar que a vazão supere os $6.000 \mathrm{~m}^{3} / \mathrm{s}$ nas maiores cheias de cada ano. Através da regionalização de vazões, estima-se que a maior vazão média diária em cada ano é de, aproximadamente, $7.900 \mathrm{~m}^{3} / \mathrm{s}$ próximo à foz do rio (Ponto 1) e $7.000 \mathrm{~m} / \mathrm{s}$ na seção Lajeado/Estrela (Ponto 6). Convém ressaltar que este valor se refere às vazões médias diárias, o que significa que a vazão no momento do pico da cheia deve ser maior.

No rio Taquari-Antas, no trecho a montante de Muçum (entre os pontos 10 e 24), não é possível identificar apenas um tipo de fenômeno, podendo ocorrer tanto inundações quanto enxurradas. Trata-se de um longo trecho de rio em um vale mais encaixado, sem a presença de grandes áreas planas e com poucos depósitos sedimentares, predominantemente alúvios e colúvios com sedimentos mais grosseiros, que indicam uma elevada competência deste rio e processos de movimentos de massa. Na porção mais a montante (Pontos 12, 13, 14, 15 e 24) evidencia-se um forte controle estrutural ao longo de lineamentos geológicos, com presença de trechos retilíneos, cotovelos e curvas em ângulos retos.

Os poucos depósitos existentes no trecho e o aumento da declividade no trecho favorecem a ocorrência de enxurradas, embora não seja possível descartar eventos mais graduais. Isso porque a área de drenagem neste trecho está no intervalo entre 2.000 (Ponto 24) e $16.000 \mathrm{~km}^{2}$ (Ponto 10), o comprimento do rio a montante varia entre $145 \mathrm{~km}$ e $425 \mathrm{~km}$, o que indica um tc entre 27 h (Ponto 24) e 72 h (Ponto 10). Estes índices corroboram com a possibilidade de eventos mais lentos e graduais, embora as evidências geomorfológicas indiquem a ocorrência de respostas rápidas no nível do rio.

Outros rios apresentam características gerais semelhantes ao trecho analisado no parágrafo anterior, com vales mais estreitos e poucos depósitos fluviais, além da presença de sedimentos grosseiros (cascalhos ou maiores) nas margens. É o caso dos rios da Prata (Pontos 16 e 17), Forqueta (Pontos 18, 21, 22 e 23), Carreiro (Pontos 19, 26 e 27), Guaporé (Pontos 20 e 25), Tainhas (Ponto 28) e Fão (Ponto 29). Tratam-se de rios com área de drenagem aproximada entre $1.300 \mathrm{~km}^{2}$ e $3.800 \mathrm{~km}^{2}$, com tc entre $17 \mathrm{~h}$ e $36 \mathrm{~h}$. Estes valores indicam que a resposta pode ser gradual, embora as evidências geomorfológicas indiquem a ocorrência de respostas rápidas e variações bruscas no nível do rio, típico das enxurradas.

Como exemplo, pode-se mencionar a enxurrada ocorrida na bacia do rio Forqueta em janeiro de 2010. Na cidade de Marques de Souza, as águas do rio Forqueta subiram tão rapidamente que os moradores sequer tiveram tempo de recolher seus pertences ou deslocar seus animais nos estabelecimentos rurais. Muitas propriedades situadas próximas às áreas ribeirinhas, baseadas em agricultura e pecuária, foram destruídas por completo. Além disso, diversos campings tiveram suas estruturas arrasadas pelas águas. Em torno de 100 famílias ficaram desalojadas, muitas delas sendo resgatadas dos telhados de suas residências. A BR-386, que cruza o município, ficou submersa por até um metro de água em vários pontos (Santos, 2010). Duas pontes, entre os municípios de Barros Cassal e Fontoura Xavier, foram totalmente destruídas pela enxurrada na bacia.

A enxurrada que ocorreu em 04/01/2010 é considerada a pior da história da cidade, pois causou a inundação de $60 \%$ do perímetro urbano, ultrapassando em estragos e nível de água a histórica cheia de 1941. Em decorrência disso, alguns campings foram completamente destruídos 
e 28 residências desapareceram. Os cemitérios no bairro Tamanduá foram destruídos pela enxurrada, lápides apareceram quebradas, mausoléus navegaram para a estrada, e ossadas ressurgiram no meio da plantação de trigo. Dezenas de corpos de animais foram encontrados a centenas de $\mathrm{km}$ de distância (Da Cas, 2015).

Nas áreas adjacentes aos exutórios de alguns afluentes do rio Taquari, tais como o rio TaquariMirim (Ponto 40), o arroio Boa Vista (Ponto 41), o arroio Castelhano (Ponto 42), o arroio Jacaré (Ponto 44), o arroio Santa Cruz (Ponto 51), o arroio Estrela (Ponto 54), o arroio Capivara (Ponto 57), o arroio Bonito (Ponto 60) e o arroio do Potreiro (Ponto 61) podem ocorrer inundações e enxurradas. Porém, neste caso, as inundações são causadas pelo avanço das águas do rio Taquari em direção a suas planícies, bem como pelo represamento das águas destes arroios, impedindo a saída da água do sistema. Tratam-se de bacias com área de 90 a $630 \mathrm{~km}^{2}$, que deságuam diretamente no rio principal, onde ocorre o remanso das águas (Figura 5). Eventualmente, podem ocorrer também enxurradas, normalmente em situações de chuvas mais localizadas nas suas respectivas áreas de drenagem. Quando isto ocorre, a resposta é mais rápida e os volumes envolvidos são bem inferiores aos casos de inundações graduais.

Quanto aos pontos referentes apenas ao processo de enxurradas, os mesmos estão bem distribuídos pela bacia, embora predominem na porção centro-jusante, tendo em vista as características geomorfológicas favoráveis para a concentração das águas e os desníveis topográficos mais acentuados (Figura 5). Nesta categoria, pode-se destacar os seguintes: i) rio da Telha (no Ponto 30), com área de drenagem de $1.188 \mathrm{~km}^{2}$ e tc de 19,5 horas; ii) rio Guaporé (no Ponto 31), com área de drenagem de $1.155 \mathrm{~km}^{2}$ e tc de 17,8 horas; iii) rio Turvo (no Ponto 32), com área de drenagem de $1.067 \mathrm{~km}^{2} \mathrm{e}$ tc de 19,5 horas; iv) rio Lajeado Grande (no Ponto 33), com área de drenagem de $943 \mathrm{~km}^{2}$ e tc de 16,2 horas; v) rio Tainhas (no Ponto 34), com área de drenagem de $928 \mathrm{~km}^{2}$ e tc de 16,5 horas.

Outros arroios apresentam uma resposta mais rápida (tc $<10 \mathrm{~h}$ ), dentre os quais pode-se mencionar o rio Refugiado (Ponto 35), o arroio Boa Vista (Ponto 48), o arroio Castelhano (Pontos 49 e 58), o arroio Forquetinha (Ponto 50), o arroio São Tomé (Ponto 52), o arroio
Santa Cruz (Ponto 56) e o arroio Estrela (Ponto 59). Nestes pontos, embora o evento seja brusco, os volumes envolvidos são menores, dificilmente ultrapassando os $500 \mathrm{~m}^{3} / \mathrm{s}$.

A bacia do Taquari-Antas apresenta 2.100 $\mathrm{km}^{2}(8 \%)$ de áreas suscetíveis a inundações e enxurradas. Quanto à relação entre as áreas suscetíveis e os limites municipais, se destacam os seguintes municípios: Venâncio Aires (228 $\mathrm{km}^{2}$ ), Taquari (152 $\left.\mathrm{km}^{2}\right)$, General Câmara (127 $\left.\mathrm{km}^{2}\right)$, Passo do Sobrado $\left(95 \mathrm{~km}^{2}\right)$, Estrela $(73$ $\left.\mathrm{km}^{2}\right)$ e Cruzeiro do Sul $\left(71 \mathrm{~km}^{2}\right)$. A maior parte destas áreas (>95\%) se referem a usos agropecuários diversos (pastagens, lavouras temporárias, lavouras permanentes), banhados, áreas de mata ciliar e florestas industriais exóticas (Eucaliptos, Acácias e Pinus). Considerando apenas as áreas urbanizadas (69 $\mathrm{km}^{2}$ de áreas suscetíveis), os municípios que apresentam maior área suscetível são Estrela $\left(7,8 \mathrm{~km}^{2}\right)$, Lajeado $\left(6,8 \mathrm{~km}^{2}\right)$, Venâncio Aires $\left(6,2 \mathrm{~km}^{2}\right)$ e Arroio do Meio $\left(4,6 \mathrm{~km}^{2}\right)$.

Outros municípios com registros de inundações e enxurradas são Encantado, Roca Sales, Cruzeiro do Sul, Triunfo, Marques de Souza, Teutônia, Muçum, Taquari e Santa Tereza.

De fato, Estrela e Lajeado são os dois municípios que mais decretaram Situação de Emergência no Estado do RS, entre os anos de 1980 e 2012, com 17 e 13 decretos, respectivamente, conforme levantamento apresentado por Sausen \& Reis (2013). O resultado do cruzamento entre as áreas suscetíveis e as áreas urbanizadas indica realmente que estes dois municípios apresentam, possivelmente, os maiores prejuízos econômicos e sociais em relação às inundações na bacia.

Por fim, deve-se destacar a importância de aprofundar e qualificar os índices obtidos, bem como os critérios e metodologia de mapeamento, baseando-se em um maior conjunto de relatos e registros de campo para validação e também em novos dados obtidos por sensoriamento remoto para refinar os contornos das áreas de inundação. Estudos em escala regional, como o apresentado neste trabalho, também são importantes para um planejamento mais eficiente dos municípios inseridos na bacia, buscando reduzir os prejuízos inerentes aos processos hidrológicos extremos. O mapeamento regional pode servir de base para a elaboração de estudos mais aprofundados, em escala local, visando à reorganização do espaço, 
no sentido de redirecionar o crescimento das cidades e das atividades agropecuárias, em função dos desastres que ocorrem na bacia hidrográfica do Taquari-Antas.

\section{CONCLUSÕES}

O objetivo do presente estudo foi mapear e caracterizar as áreas suscetíveis a inundações e enxurradas na bacia do rio Taquari-Antas. O mapeamento das áreas suscetíveis foi realizado por meio da simulação do aumento do nível da água nos rios, com base em um MDE. A metodologia adotada permitiu atingir os resultados necessários para atender ao objetivo geral.

Quanto à definição do tempo de concentração, parâmetro importante para diferenciar as inundações das enxurradas, a equação que apresentou maior eficiência foi a de Kirpich, embora este tenha apresentado uma tendência de superestimar o tempo de concentração em bacias maiores (rio Taquari) e de subestimar os valores em bacias um pouco menores (os afluentes que apresentam represamento das águas em virtude das cheias no rio principal), como no caso do rio Forqueta. Deve-se ressaltar que a análise do tempo de concentração reforçou a necessidade de aprofundar os estudos sobre a resposta hidrológica de um rio em relação às chuvas, tendo em vista que as equações utilizadas apresentam erros consideráveis. Para tanto, seria necessário ampliar o monitoramento em tempo real dos rios, em intervalo de tempo horário ou inferior.

Além disso, deve-se destacar a síntese realizada em relação às vazões máximas em diferentes locais com ocorrência de inundações e enxurradas. Esses valores foram obtidos por meio de um processo de regionalização de vazões. A curva regional obtida apresentou um ajuste satisfatório $\left(\mathrm{R}^{2}=0,935\right)$. Com base na curva regional, conclui-se que a vazão máxima anual do rio Taquari se aproxima de $7.900 \mathrm{~m} 3 / \mathrm{s}$ no seu trecho final, junto à foz no rio Jacuí. Em TRs maiores, a vazão média diária pode ultrapassar $20.000 \mathrm{~m}^{3} / \mathrm{s}$ no trecho baixo do rio Taquari.
Com base nos resultados obtidos em relação ao mapeamento, conclui-se que bacia apresenta processos distintos. No rio Taquari, no trecho a jusante de Encantado, o fenômeno predominante são as inundações. No rio Taquari-Antas, no trecho entre os rios Guaporé e Tainhas, foi possível identificar tanto inundações quanto enxurradas, assim como nos afluentes maiores (rios da Prata, Forqueta, Carreiro, Guaporé, Tainhas e Fão). Por sua vez, quanto aos pontos referentes apenas ao processo de enxurradas, os mesmos estão bem distribuídos pela bacia hidrográfica, embora predominem em bacias da porção centro-jusante, tendo em vista as características geomorfológicas favoráveis para a concentração das águas e os desníveis topográficos mais acentuados.

Ainda sobre o mapa de suscetibilidade às inundações e enxurradas, conclui-se que aproximadamente $8 \%$ da área total da bacia pode ser atingida por tais eventos extremos. Porém, a maior parte destas áreas (>95\%) se referem a usos agropecuários diversos (pastagens, lavouras temporárias, lavouras permanentes), banhados, áreas de mata ciliar e florestas industriais exóticas. Considerando apenas as áreas urbanizadas suscetíveis $\left(69 \mathrm{~km}^{2}\right)$, os municípios que apresentam maior área suscetível são Estrela, Lajeado, Venâncio Aires e Arroio do Meio. Por fim, deve-se destacar a importância de aprofundar e qualificar os índices obtidos, bem como os critérios e metodologia de mapeamento, baseando-se em um maior conjunto de relatos e registros de campo para validação e também em novos dados obtidos por sensoriamento remoto para refinar os contornos das áreas de inundação. Estudos em escala regional são importantes para um planejamento mais eficaz dos municípios e da Defesa Civil, buscando estratégias diferenciadas para reduzir os custos inerentes aos processos hidrológicos extremos.

\section{REFERÊNCIAS}

ALCÁNTARA-AYALA, I. Geomorphology, natural hazards, vulnerability and prevention of natural disasters in developing countries. Geomorphology, v. 47, n. 2, p. 107-124, 2002.

CASTRO, A.L.C. Glossário de defesa civil estudos de riscos e medicina de desastres. Ministério do Planejamento e Orçamento, Secretaria Especial de Políticas Regionais, Departamento de Defesa Civil, 1998.

CHOW, V.T.; MAIDMENT, D.R.; MAYS, L.W. Hidrología
Aplicada. Tradução JUAN, G.S. Santafé de Bogotá, Colômbia: McGRAW-HILL Interamericana S.A., 1994. 584p. CRED-CENTRE FOR RESEARCH ON THE EPIDEMIOL OGY OF DISASTERS. The international disaster database (EM-DAT). 2015. Disp. em: <http://www.emdat.br/dat abase>. Acesso em: 21 dezembro 2015.

DA CAS, R. Estudo da influência da PCH Salto Forqueta na enchente de 4 de janeiro de 2010. Trabalho de Conclusão de 
Curso-Engenharia Civil, Lajeado: Centro Universitário Univates, 2015

ECKHARDT, R.R. Geração de Modelo Cartográfico Aplicado ao Mapeamento das Áreas Sujeitas às Inundações Urbanas na Cidade de Lajeado / RS. Porto Alegre, 2008. Dissertação (Mestrado em Sensoriamento Remoto) Universidade Federal do Rio Grande do Sul.

FERRI, G. \& TOGNI, A.C. A história da bacia hidrográfica Taquari-Antas. Lajeado: Ed. da Univates, 2012.

FRANK, B.; SEVEGNANI, L.; TOMASELLI, C.C. Desastre de 2008 no Vale do Itajaí: água, gente e política. Blumenau: Agência de Água do Vale do Itajaí, p. 24, 2009.

HASENACK, H. \& WEBER, E.J. (Org.). Base cartográfica vetorial contínua do Rio Grande do Sul-escala 1:50.000. Porto Alegre: UFRGS-IB-Centro de Ecologia, 2010. DVD (Série Geoprocessamento, 3).

IRIMESCU, A.; STANCALIE, G.; CRACIUNESCU, V.; FLUERARU, C.; ANDERSON, E. Remote sensing and GIS techniques for flood monitoring and damage assessment. Study Case in Romania. BALWOIS, 2010.

JENSON, S.K. \& DOMINGUE, J.O. Extracting topographic structure from digital elevation data for geographic information system analysis. Photogrammetric engineering and remote sensing, v. 54, n. 11, p. 1593-1600, 1988.

KUREK, R.K.M. Análise das inundações no Vale do Taquari/RS como subsídio à elaboração de um modelo de previsão. Santa Maria, 2016. Dissertação (Mestrado em Engenharia Civil) -Universidade Federal de Santa Maria.

MARENGO, J.A. Mudanças climáticas e eventos extremos no Brasil. Fundação Brasileira para o Desenvolvimento Sustentável-FBDS. 2010. Disp. em: <http://www.fbds. org.br/fbds/IMG/pdf/doc-504.pdf>. Acesso em: 18 dezembro 2015.

OLIVEIRA, G.G.; GUASSELLI, L. A., BRUBACHER, J. P., \& SIRANGELO, F. R. Interpretação e mapeamento geomorfológico da bacia hidrográfica do rio Taquari-Antas, com suporte de técnicas de geoprocessamento e utilização de dados orbitais e cartográficos. In: SIMPÓSIO BRASILEIRO DE SENSORIAMENTO REMOTO, 17, 2015, João Pessoa. Anais... João Pessoa: INPE, p. 6467-6474.

OLIVEIRA, G.G. Modelos para Previsão, Espacialização e Análise das Áreas Inundáveis na Bacia Hidrográfica do Rio Caí, RS. Porto Alegre, 2010. Dissertação (Mestrado em Sensoriamento Remoto) - Universidade Federal do Rio Grande do Sul.

OLIVEIRA, G.G.; GUASSELLI, L.A.; SALDANHA, D.L. Modelos de previsão e espacialização das áreas inundáveis em
Montenegro, Rio Grande do Sul, Brasil. Revista Brasileira de Geomorfologia, v. 13, n. 4, 2012.

PAZ, A.R. \& COLLISCHONN, W. Derivação de rede de drenagem a partir de dados do SRTM. Revista Geográfica Acadêmica, v. 2, n. 2, p. 84-96, 2008.

SANTOS, E.; Enchente no Rio Taquari-Janeiro de 2010. Apena-ONG. <http://estrela-rs-aepan.blogspot.com.br/2010/ 01/enchente-no-rio-taquari-janeiro-de-2010.html>. Acesso em: 12 março 2015.

SANTOS, R.F. (org.) Vulnerabilidade Ambiental. Ministério do Meio Ambiente (MMA). Brasília, 2007.

SAUSEN, T.M. \& REIS, J.T. Levantamento e avaliação das inundações ocorridas no Rio Grande do Sul. In: Eventos Extremos no Rio Grande do Sul: inundações e movimentos de massa. GUASSELLI, L. A.; OLIVEIRA, G. G.; ALVES, R. C. M. (org.) Porto Alegre: Evangraf, 2013. p. 208.

SILVEIRA, A.L.L. Desempenho de formulas de tempo de concentração em bacias urbanas e rurais. Revista Brasileira de Recursos Hídricos, v. 10, n. 1, p. 5-23, 2005.

SIRANGELO, F.R. Relação entre a ocorrência de inundações e enxurradas e os índices morfométricos das sub-bacias hidrográficas da Região Hidrográfica do Guaíba, Rio Grande do Sul, Brasil. Porto Alegre, 2014. Dissertação (Mestrado em Sensoriamento Remoto), Universidade Federal do Rio Grande do Sul.

TUCCI, C.E.M. Hidrologia: ciência e aplicação. 4. Ed. Porto Alegre: Editora da UFRGS/ABRH, 2014. 943p.

TUCCI, C.E.M.\& BERTONI, J.C. (org.) Inundações Urbanas na América do Sul. $1^{\mathrm{a}}$ ed. Porto Alegre: Associação Brasileira de Recursos Hídricos, 2003.

UNESCO. 2012. WORLD WATER DEVELOPMENT REPORT (WWDR4), 2012. Disp. em: <http:// www.unesco.org/new/en/natural-sciences/environment/water/ wwap/wwdr/wwdr4-2012/>. Acesso em: 03/09/2013.

VALERIANO, M.M. Topodata: guia para utilização de dados geomorfológicos locais. Instituto Nacional de Pesquisas Espaciais. INPE-15318-RPQ/818. São José dos Campos: INPE, 2008. 73 p. Disp. em: <mtc-m18.sid.inpe.br/col/ sid.inpe.br/mtc-m18@80/2008/07.11.19.24/doc/publicacao. pdf>. Acesso em: 06/05/2014. 